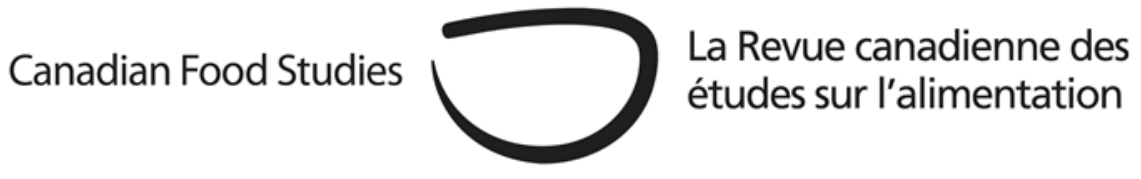

Original Research Article

\title{
Understanding social economy through a complexity lens: Four case studies in Northwestern Ontario
}

Connie H. Nelson*, Mirella L. Stroink, Charles Z. Levkoe, Rachel Kakegamic, Esther McKay, William Stolz, Allison Streutker

Lakehead University

\begin{abstract}
Broadly described, the social economy refers to a series of initiatives with common values representing explicit social objectives. The roots of social economy organizations predate the neoliberal economy and are integral to the human condition of coming together in mutual support to address challenges that benefit from collective efforts. Drawing on a complexity science approach, this paper analyzes four case studies situated in Northwestern Ontarioblueberry foraging, Cloverbelt Local Food Co-op, Willow Springs Creative Centre and Bearskin Lake First Nations - to demonstrate key features of social economy of food systems. Their unifying feature is a strong focus on local food as a means to deliver social, economic and environmental benefits for communities. Their distinct approaches demonstrate the importance of context in the emergence of the social economy of food initiatives. In the discussion section, we explore how these case study initiatives re-spatialize and re-socialize conventional food system approaches.
\end{abstract}

Keywords: social economy; food systems; complexity science; complex adaptive systems; foraging; context 
Introduction

Since the 1970s, neoliberalism is the predominant form of social and economic relations and has led to rising inequality, ecological degradation and a breakdown of the welfare state (Heynan, McCarthy, Prudham, \& Robbins, 2007; Restakis, 2006). The social economy predates the neoliberal economy and is deeply integral to the human condition of addressing challenges through collective efforts (Defourny \& Develterre, 1999; Jennings, 2012). In this way, social economies address the limitations of the profit-driven, free market approach. Broadly described, the social economy refers to a series of initiatives with common values representing explicit social objectives (Amin, Cameron, \& Hudson, 2002; Moulaert \& Ailenei, 2005).

The term social economy first appeared in France in the early $19^{\text {th }}$ century; however, the legal framework that formalized entities like cooperatives and non-profits that make up the modern social economy did not arise until the end of the $19^{\text {th }}$ century (Defourny $\&$ Develterre, 1999). The diversity of conditions in which people associated for cooperative and mutual assistance resulted in the modern social economy being forged from the interplay of many ideologies including socialist movements that promoted producer cooperatives and dominated the international workers movement. This pluralistic ideological legacy continues to shape the diversity and breadth of applications of social economy including co-operatives, non-profits and social enterprises (Moulaert \& Ailenei, 2005). The concept was first used in Canada in 1992 where Quebec has played a leadership role in its development (Downing, McElroy, Tremblay, \& Amyot, 2012; Charron, 2012; and Mendell \& Neamtam, 2009).

To explore the social economy in Northwestern Ontario, this paper presents four case studies to demonstrate key features of social economy of food systems. These case studies are linked by their focus on local food as a means to deliver social, economic and environmental benefits for communities, and by their adaptive emergence within the shared context of Northwestern Ontario. Their distinct approaches reveal the complexity of social economy of food initiatives and their rootedness in social and physical context. Each case study is presented using the unique voices of those involved in an attempt to remain true to our community-based methodology. This is also a way to share the perspectives of the people and communities along with the diversity of social economies that have emerged in Northwestern Ontario.

We argue that complex adaptive systems theory is a useful theoretical approach within which to understand social economy initiatives. Following an introduction to the relevant literature and our analytical approach, we provide an overview of the Northwestern Ontario region and our research methodology. We then present an analysis of each case study that explores how they provide social, economic and environmental benefits that enhance community prosperity. We conclude by suggesting that these initiatives re-spatialize and re-socialize conventional food system approaches. 
The social economy

Defourny and Develterre (1999) maintain that social economy initiatives develop out of "conditions of necessity" (p. 22). Since the 1980's, there has been a re-emergence of interest in the social economy that is linked to global shifts including the decline of industrialization and the ability of the welfare state to meet basic human needs. Hudson (2009) suggests that currently there are three basic positions on social economy.

First, there is the perspective that social economy works in parallel with the mainstream economy and is a safety net for those who are marginalized. Secondly, the social economy has disruptive qualities with the potential to transform to a post-capitalist future (p. 508). Thirdly, according to Hudson, the perspective most widely discussed in the literature is the position that the social economy is neither an adjunct to the mainstream economy nor a replacement of it, but is an alternative that emerges in parallel to, and at times in competition with, mainstream capitalism.

Notably, Moulaert and Ailenei (2005) explain that in the sociological literature of the 1980s, the term was employed to include activities rejecting the capitalist market. More recently when the public or private sectors are unable to meet collective needs and there is a crisis in the mainstream economy, the social economy re-emerges as an alternative vision playing a complementary or supplementary role instead of a subversive one (Golob, Podnar \& Lah, 2009; Moulaert and Ailenei 2005; Myer, 2009). Jennings (2012) cautions that social economy initiatives should not be viewed as the transfer of responsibilities from the state to social economy initiatives. Rather, they suggest a unique parallel role for the social economy to the market and state where a diversity of issues specific to community and local place are addressed.

Social economy initiatives provide an alternative model that can reconnect communities with unique local attributes, which can enhance local strengths and resilience (Sonnino \& Griggs-Trevarthen, 2013). Malloy et al. (1999) suggest an emphasis on the primacy of people's needs where the focus is on building social capacity and responding to under-met needs. While there is no unifying definition of the social economy (Moulaert \& Ailenei, 2005), Sonnino and Trevarthen-Griggs (2013) identified one common feature of social economy throughout the literature: "the synergy between economic and social goals, rather than the pursuit of profit" (p. 274).

The place-based and contextual nature of the social economy makes it difficult to establish a clear definition (Hun \& Endo, 2016; Kay, 2006; Moulaert \& Ailenei, 2005; Myers, 2009). This decentralized nature has led to the recognition of a different type of social economy that is generally community-based, functioning with fewer government interventions in both formal and informal sectors (Defourny \& Develterre, 1999). Social economies arise organically within a specific locality, but even when relatively small, these initiatives can have profound impacts through large-sector social and structural changes (Downing et al., 2012). Thus, we suggest an articulation of the social economy as a fluid concept, rather than attempting to take characteristics of one place and apply them in another location (Myers, 2009). Place and 
community are important anchors for engagement in a social economy and for collective mobilization of local resources. Attempts to develop a one size fits all definition or model is to write out specificity of both project and place and thus decontextualize social economy initiatives (Amin, Cameron \& Hudson, 2002).

While its application remains specific to locality, there is consensus on the core principles of social economy. The following principles whose origins are credited to Chantier de l'economie sociale (2013) are now widely accepted as central principles of a social economy that work well for both market and social-oriented activities (Canadian Community Economic Development Network, 2008; Defourny \& Develterre, 1999;):

1. placing service to its members or the community ahead of profit;

2. autonomous management;

3. a democratic decision-making process

Key to a social economy is the emphasis on benefit to its members and/or the wider community rather than generating profits for further capital investment. The autonomy in management places emphasis on participation and community empowerment and further distinguishes the social economy from the production of goods and services by government. A democratic decision-making process places emphasis on respect for equity in participation of all, mutuality and cooperation.

A complexity science approach

Our study builds on research that has applied a complexity science approach to various complex social ecological systems, including food systems (Holling, 2001; Matei \& Antonie, 2015; Morcol, 2014; Nelson \& Stroink, 2014; Randle, Stroink \& Nelson, 2014; Stroink \& Nelson, 2013). In this paper, we argue that a complexity science approach is useful in conceptualizing social economies of food. This approach draws on theories and concepts from several disciplines, including complex systems theory and complex adaptive systems theory (Mitchell, 2009). All complex systems are characterized as a collection of independent agents that act in unpredictable ways; yet whose actions are interconnected in a network such that one agent's actions change the context for other agents. These other agents then adapt to their changed context by changing their own behavior.

In a food system, the individual agents include consumers, producers, and processors, and these agents are independent yet interdependent in a network, affecting each other and responding adaptively to their contexts which include biophysical, social, and economic aspects of place. Thus, through dense interactions or connections, a complex system as a whole produces outcomes that cannot be predicted by any individual actions. As a result of these 
interdependencies, complex systems may produce emergent behavior that is highly sensitive to initial conditions, where slight variations cascade and multiply, and ultimately produce major differences, and their emergent behavior may appear unpredictable and non-linear. Thus, system properties are best understood as patterns that adapt and change over time. Patterned outcomes, including social economy of food initiatives, emerge out of these interactions.

Complex adaptive systems (CAS) are able to learn from experience, altering their behavior in response to changes in the context and adapting dynamically through feedback loops (Holland, 2006; Ostrom, 1990; Ostrom, 2010; Stacey, 1996). Feedback loops that are tighter, that return information to the system on the effects of its emergent outcomes more quickly, enable the system to be more responsive to its environment. Complex adaptive systems also exist across scales and are nested within one another. Each level can thus be both its own complex adaptive system and an individual element within a broader CAS. As a result of interactions across these scales, complex adaptive systems are both affected by and affect emergent properties at different scales. Such systems are constantly adapting and evolving.

The self-organizing adaptive behaviour in complex adaptive systems is now widely referred to in terms of four phases of the adaptive cycle. The widespread use of the adaptive cycle is based on the early work of Holling from his patterning observations of the cycles of forest ecosystems following disturbance (Gunderson \& Holling, 2002). In the adaptive cycle as shown in Figure 1, the CAS moves through the phases of exploitation, conservation, release and reorganization. As the interdependent agents in the CAS interact with each other and their context, adapting dynamically through feedback loops, patterned behavior begins to emerge out of what is initially more diverse and chaotic behaviour.

If the pattern is adaptive it becomes supported with stabilizing structures that serve to store capital and energy within the system. For example, in Stroink and Nelson (2013), the relevance of the adaptive cycle to the evolving nature of local food systems in Northern Ontario is described using five case studies. In a food system, this capital includes skills, knowledge, human energy, and economic wealth; stabilizing structures include legislation, policy, and physical infrastructure (Nelson \& Stroink, 2014). With increasing stability, the system moves from exploitation (growth) to conservation. In conservation, the stabilizing structures provide efficiency but also undermine diversity and resilience as the system's energy and resources are consumed in maintaining the stabilizing structure and the system's ability to adapt quickly to the context declines. Release occurs when the system's structure collapses into a more chaotic state, often following a triggering event, and is followed by a phase of reorganization as agents from the collapsed system begin interacting in diverse new ways (Gunderson \& Holling, 2002; Walker \& Salt, 2006).

As complex adaptive systems, social economy of food initiatives are highly sensitive to contextual factors in place. Indeed, the particular role of place in social economy is noted throughout the literature (Defourney \& Develterre, 1999; Hun \& Endo, 2016; Kay, 2006; Moulaert \& Ailenei, 2005; Myers, 2009). We now turn to examine how the place-based context 
of Northwestern Ontario has shaped our social economy of food case studies along with our research methodology.

Figure 1: The Adaptive Cycle of Growth and Release*

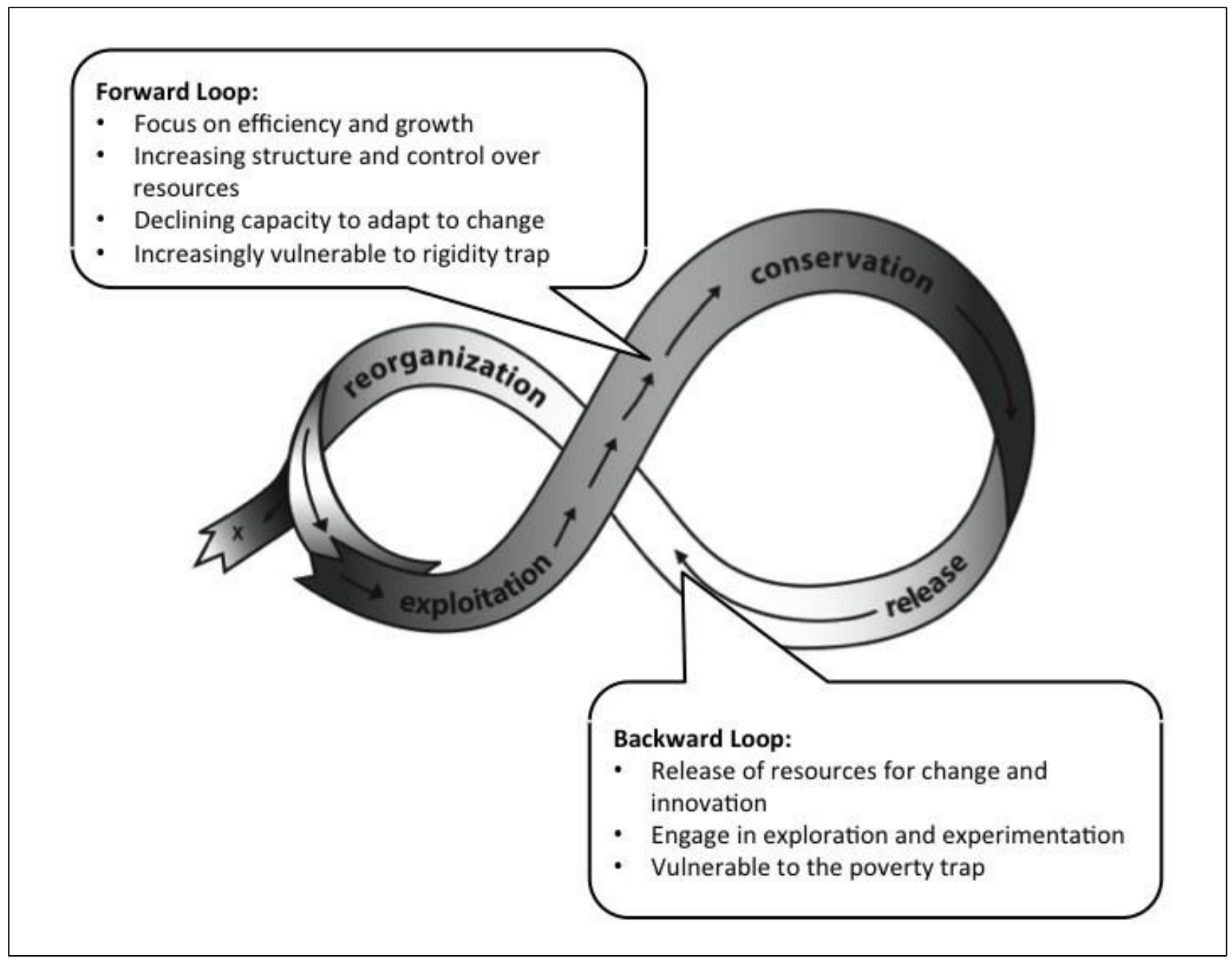

* Based on Holling, 1986, 2001; see also Stroink \& Nelson, 2013

Overview of the study region, methodology and the case studies

Overview of the study region

Northwestern Ontario is comprised of Thunder Bay, Rainy River and Kenora Districts, the three most western districts in Ontario; and covers an area of $526,417 \mathrm{~km}^{2}$, which is about 57.9 percent of the land area of Ontario (see Figure 1). The population of Northwestern Ontario is 231, 691 
(Statistics Canada 2016) with Thunder Bay and surrounding satellites comprising the only area with over 100,000 people. There are four treaties signed between settler governments and Indigenous populations of Ojibway, Cree and OjiCree tribes located in 88 First Nations in Northwestern Ontario. These treaties maintain the right of Indigenous peoples to hunt, fish and gather as they had done for centuries and permitted for the sharing of land and resources. The Robinson Superior Treaty was the first treaty in Canada to explicitly protect the hunting and fishing rights of Indigenous people in the territory (Nokiiwin Tribal Council, nd). Diverse interpretations of the meaning of these treaties on access to traditional food sources remain. The Indian Act of 1876 further challenged historic access to land and resources through the reserve system that limited traditional mobility to hunt and fish. The introduction of treaties and the Indian Act into the traditional food practices of Indigenous people meant that heretofore unfettered mobility was compromised.

Figure 2: Districts of Northwestern Ontario

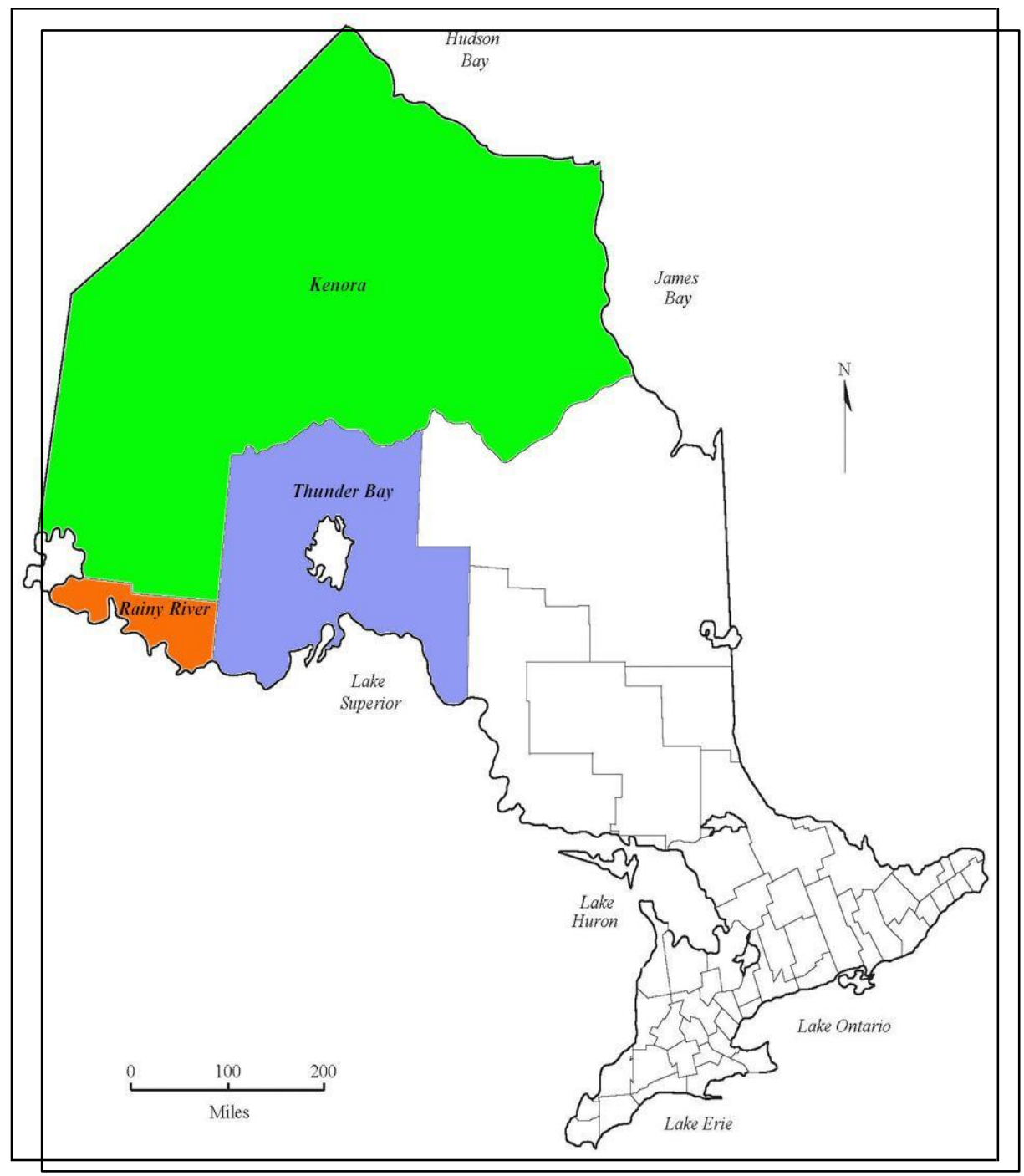


Source: Modified from Brock University Map Library (Brock University, 2012)

Northwestern Ontario is bounded by key landscape features, including the province of Manitoba to the west, Hudson Bay to the north, Lake Superior to the south, and the irregular eastern boundary of James Bay, the Albany River and then south to the municipality of White River. The landform features are primarily of glacial origin circa 9-10,000 BP (Sims \& Baldwin, 1991). This includes the vast waterways that flow north to Hudson Bay or south to Lake Superior, the largest surface area of fresh water in the world, and provide an abundance and diversity of fish for food; scattered rich deposits of clay laid down by glacial streams and lakes that support grain and vegetable production; as well as notable lush pastures for animal production; and sandy soil a legacy of glacial rebound that yields an abundance of native wild blueberries. Northwestern Ontario features areas with Agriculture Soil Classed 2 to 4 soils that are suitable for sustained production of common field crops (Natural Resources Canada 1969).

The region has a number of unique food resources that are not classified by the Ontario Ministry of Agriculture, Food and Rural Affairs (OMAFRA) as agricultural foods and thus may not be eligible for agriculture funding. These food sources include a diversity of native fish species, native wild rice, blueberries, saskatoons, mushrooms, and wild meats such as moose, geese and spruce grouse. Wild meats are prohibited from market sales and fish must be obtained through a commercial license. These regulations may also limit opportunities to develop the culinary aspects of northern tourism (Stroink \& Nelson, 2013).

For food production, climate change is expected to have major implications for the length of the growing season, the variety of crops grown, as well as grain yields in Northern Ontario. It is predicted that climate change will increase growing days in Northern Ontario by 30-45 days by mid-century pointing to emerging growing opportunities and challenges due to earlier springs and later falls (Qian et al. 2005, Cummings 2009 a-c). Other challenges for access to both native plant, animal and fungi food sources include competitive land uses such as mining and logging as well as related potential contamination.

\section{Methodology and the case studies}

This research was part of a larger project studying the informal, under-recognized contributions of the social economy of food to community prosperity. Funded by the Social Science and Humanities Research Council of Canada (SSHRC), the research focused on areas of the social economy of food that are often overlooked. The aim was to identify ways that learnings could benefit those most impacted by the dominant food system including low-income groups, Indigenous people, youth and women. Inviting collaborative research teams to focus on key geographic regions, the intention was to share research findings among the broader network through articles, workshops, and videos. 
To explore the social economy of food in Northwestern Ontario, we adopted a community engaged research methodology. The case studies were originally chosen to represent breadth in diversity of the types of social economies that have emerged in Northwestern Ontario. As food studies researchers committed to community-based approaches, we had pre-existing relationships that had existed for over a decade. These previous engagements facilitated trust with the people and knowledge about each social economy initiative. This involved conducting four case studies and working directly with community partners who were engaged in foodrelated social economies. The cases focused on blueberry foraging, an on-line regional food distribution system, a community-based food market and use of boreal plants for therapeutic healing, and on a remote Northern First Nation. Research was conducted between November 2016 and March 2018 through a series of qualitative and quantitative methods (see Table 1). In all cases, research was co-designed and implemented in collaboration with the community partners.

Table 1: Social Economy of Food System Case studies

\begin{tabular}{|c|c|}
\hline Case Study (links to additional case study materials) & Key Methods Used \\
\hline $\begin{array}{l}\text { Blueberry Foraging } \\
\text { http://nourishingontario.ca/blueberry-foraging-as-a-social- } \\
\text { economy -in-northern-ontario/ }\end{array}$ & $\begin{array}{l}\text { participant observation before, during and after the } \\
\text { blueberry harvest; } \\
\text { Semi-structured interviews ( } n=34 \text { ) with key knowledge } \\
\text { holders from each blueberry initiative }\end{array}$ \\
\hline $\begin{array}{l}\text { Cloverbelt Local Food Co-op } \\
\text { http://nourishingontario.ca/the-cloverbelt-local-food-co-op/ }\end{array}$ & $\begin{array}{l}\text { farmers, growers, processors }(n=3) ; \text { board members } \\
(n=2) \text {; staff }(n=2) \text {; stakeholder organizations }(n=2) ; \\
\text { community members }(n=3) \text {; focus group of producers, } \\
\text { processors, board members, staff, and community } \\
\text { members }(n=9)\end{array}$ \\
\hline $\begin{array}{l}\text { Willow Springs Creative Centre } \\
\text { http://nourishingontario.ca/willow-springs-creative-centre/ }\end{array}$ & $\begin{array}{l}\text { survey of market customers to understand } \\
\text { demographics as well as what motivates customers to } \\
\text { attend and purchase goods at their weekly farmer's } \\
\text { market }(n=72) \text {; survey of customers with the Soup and } \\
\text { Bread Extravaganza ( } n=47) \text {; semi-structured interviews } \\
\text { with market vendors ( } n=6) \text {; participant observation } \\
\text { with trainees }(n=3)\end{array}$ \\
\hline $\begin{array}{l}\text { Bearskin Lake First Nation } \\
\text { http://nourishingontario.ca/the-social-economy-of-food/case- } \\
\text { studies-subversions-from-the-informal-and-social-economy/the- } \\
\underline{\text { social-economy-in-northwestern-ontario/ }} \\
\text { video is under construction. For release, see Nourishing } \\
\text { Communities } \\
\text { http://nourishingontario.ca/ }\end{array}$ & $\begin{array}{l}\text { informal interviews with community members } \\
\text { engaged in accessing traditional foods, elders and } \\
\text { knowledge keepers employed by the band with special } \\
\text { responsibilities to protect and preserve traditional } \\
\text { food sources; participant observation (note: } \\
\text { researcher is a member of Bearskin Lake First Nation) }\end{array}$ \\
\hline
\end{tabular}


Once the on-site research had been completed, we met with Sheba Films ${ }^{1}$ to discuss the coproduction of four short videos that would highlight key features of each of our case studies. Each of our partners were asked to identify persons and places that they would like to see featured. Each partner has permanent access to these completed videos to use for promotion or to inform the public about their work. These videos are embedded into our analysis of the case studies for further enhancement of portraying the on-site dynamics of each of our social economies of food studies. Table 1 includes the URLs.

Four social economy case studies through a complexity science approach

Through our case study analysis, we show that complexity science provides a unique perspective on how each of the case studies demonstrate key characteristics from the social economy literature - that they prioritize social, community, and ecological benefits over profits, are autonomously managed, and democratic in structure. We further discuss how these initiatives respatialize and re-socialize conventional food system approaches as they provide social, economic and environmental benefits to their local and regional communities. We present our analysis through each case study to demonstrate how each social economy as a complex system produces outcomes that cannot be predicted by any individual actions. We look at the patterns that define a social economy through the dense and dynamic interactions that occur within each case study. Through this approach, we discuss how each of these four social economies contribute to building a local food system in Northwestern Ontario. Each social economy of food reveals that their unique contexts shape the way key characteristics of a complexity lens are exhibited.

\section{Blueberry foraging}

Wild lowbush blueberries (Vaccinium angustifolium, nigrum var., and myrtillus) are highly abundant in the boreal forest which dominates the forest landscape of Northwestern Ontario and have been part of the local diet, supporting food security since Indigenous people first arrived as the glaciers retreated 9,000-10,000 years ago (Dawson,1983). Foraging for food is thus an important part of the lives of many residents of Northern Ontario and has great economic, social, cultural, and environmental significance. People utilize local foods like wild blueberries as a source of nutrition and food security while building connections to land and a respect for nature. The connection to land that blueberry foraging provides is considered a greater priority than its potential for economic profit, consistent with the defining characteristics of social economy initiatives. While the social economy is exhibited differently in each case of blueberry foraging, as a whole the contributions of each add to a burgeoning resurgence of community control over

${ }^{1}$ https://www.shebafilms.com 
local food systems. Recent shifts toward community or locally-based management promotes opportunities for the continuation and growth of blueberry foraging as a forest food social enterprise.

Each initiative demonstrates the independent and interdependent interactions of agents. Algoma Highlands is independent in determining the size of the operation, but interdependent on the community and outside markets to expand to value-added products. Two of Algoma's markets are connected to two other social economy initiatives in Northwestern Ontario-Willow Springs Creative Centre market and Cloverbelt Local Food Co-op. Moreover, to address the need for blueberry harvesters, they innovatively employ seasonal tree-planters who rotate to blueberry picking after the tree planting season has ended. This reveals an interdependence between blueberry picking, which happens in July and August, and tree planting, which operates in May and June, extending the length of seasonal employment.

The Aroland Youth Blueberry Initiative (AYBI) is an independent initiative of the community. Currently, revenue from the initiative buys equipment for the community, such as baseball gloves, bats, balls, safety equipment, and floor hockey sticks. Purchasing equipment helps those who could not afford it otherwise and provides an opportunity for the youth to become motivated and participate in recreational activities. The AYBI recognizes that they could grow into a large business but that is not the purpose or the desire of the community.

Becoming a business is seen as unnecessary because they only want to provide support to the community and there are many rules and regulations that would need to be adhered to if they decided to expand to a larger commercial operation. As the Aroland First Nation councillor Sheldon Atlookan says, "this is the best way, the way we do it now because there is nothing holding us back, nothing in our way." In other words, the current form of the initiative allows the community to retain their independence. Autonomous decision making is indeed a defining feature of social economy initiatives. Further, the initiative provides community members with a way in which they can continue to practice traditional activities, connect with one another, and be active on the land, all important components of well-being (Stroink \& Nelson, 2009). Their interdependence is within the community itself, with the land, with other First Nation communities, and between the community and their consumers.

The boreal forest is in a constant state of disturbance and renewal which provides opportunity for native wild lowbush blueberries to establish since they are a pioneer species that colonize disturbed areas such as recently cut forestry operations and wildfire burned areas. Blueberry foraging, which exists within the complex adaptive system of the boreal forest, is found to be its own complex adaptive system that adapts to a constantly changing environment. Through blueberry harvesting, pickers were found to gain connections to the land and to each other. How these connections were expressed was impacted by the social and cultural values of individuals and communities. What appeared 
to remain consistent was the ability of the relational values associated with the social economy to support adaptation. A blueberry patch only lasts for approximately six to ten years before being out-competed by other vegetation that diminishes the light needed for the plants to produce berries. The Nipigon municipality organizes a celebration called the Nipigon Blueberry Blast that builds community connectivity and bonding around the blueberry festivities and attracts tourists that support local businesses. The Nipigon Blueberry Blast is co-evolving based on growing interest from the community to broaden the activities that celebrate the blueberry while building community relationships, sharing of blueberry stories and making new friends through increased attraction of tourists

Feedback loops enable these social economy initiatives to respond adaptively to community and historical knowledge, to the land, and to the input from consumers. Blueberry picking is part of the identity of many people in Northern Ontario as they connect with the land, and many have lifelong memories of picking berries as a child (Stolz, 2018). An increased social network of trust is built between oneself, nature, and other community members. Through this social network, blueberry picking becomes the norm, a part of the annual cycle that mutually benefits the community as food security is increased and relationships with each other and the land are strengthened. Through blueberry picking, the AYBI incorporates values for the youth around identity and connection to the land. They are taught traditional knowledge that is passed down from generation to generation around how to harvest and care for the berries.

Arthur Shupe Wild Foods is another small-scale social entrepreneurship blueberry foraging initiative. He prides himself on a reputation for having very clean berries: "Customers have told me they can take my berries and pour them right out of the basket into the pie shell". Through this blueberry initiative he has taught many community members about respect for the land while picking blueberries. Algoma Highlands Wild Blueberry Farm developed as a result of feedback from consumers from initially selling fresh and frozen blueberries to selling value-added products such as blueberry syrup, preserves, and sauces.

Each of these initiatives have thus emerged through independent yet interdependent interactions, through ongoing adaptation to the ecosystem dynamics that support blueberry growth, and in response to feedback loops from the market and community, as individuals connect in pursuit of social and ecological benefits and sustainable revenue.

\section{Willow Springs Creative Centre}

Willow Springs Creative Centre (WSCC) is an organization that offers a range of programs out of the rural village of Lappe, located about 20 kilometers northwest of Thunder Bay. Located on a winding dirt road, there are little more than two signs along the highway that advise travellers of its location. WSCC is housed in the historical international Co-op built 
by local Finnish homesteaders in 1934. It was later used as a general store, and purchased by WSCC in 2000 (Willow Springs, 2016). It is easy to imagine the old general store serving as a historic community hub, once bustling with rural locals. The smell of a wood fire hangs in the air, emanating from WSCC's signature artisan outdoor oven. There is a window that gives visitors a sneak peek into the bustling activities taking place in the commercial kitchen in the back. Painted above the window is Willow Springs' mission statement: "To promote growth through creative expression and community development."

WSCC is a not-for-profit organization employing four staff and governed by a volunteer board of directors (Willow Springs, 2016). They blend food related programs and activities with skills training for people with disabilities, art, and horticultural therapy. These activities generate revenues that are invested back into the mission of the organization, bridging the divide between consumers and producers of food while building social inclusion, food security and resilience. Overall, WSCC contributes to community development through improving inclusivity, accessibility, and quality of life, both for rural, as well as urban community members.

WSCC's use of revenues to prioritize social benefits as an autonomous entity places them within the spectrum of social economy initiatives. For example, WSCC runs a weekly market on Friday evenings from late June to late September. The Market is a bustling hub that incorporates food, celebrations, art activities, and music with a wide variety of food products sold by local vendors. Goods include local meat, cheese, produce, preserves, premade foods and local artisans' work as well as WSCC's signature artisan bread and wood fired pizza oven. The Market provides an opportunity for small, local area producers wanting to sell their goods. One vendor at the market shared that the sales made during the summer months at the market provide an important source of revenue, sometimes as much as \$200 each week. Another vendor shared memories of humble beginnings at the Market, emphasizing that the support provided from WSCC assisted them to become vendors in larger markets or even continue in their own home-based business ventures.

Most of the vendors are women interested in running a small business from home. The Market provides them with a supportive place to begin as well as assistance with kitchen certification, advertising, and developing customer service skills. Meanwhile, revenues from the Market help to sustain WSCC and draws residents and travelers to the centre. By inter-connecting various social benefit activities with each other and with revenue generating activities, WSCC enhances its resilience through internal connectedness and demonstrates a defining feature of a social economy initiative.

The Soup and Bread Extravaganza is a social enterprise program in which food from the WSCC gardens is used to provide training and skills development opportunities for young adults with disabilities or other barriers to employment (called trainees) in an industrial kitchen. Customers subscribe to the six-week supply of fresh bread and soup for a fee that is paid up front, and the food is picked up at an accessible location in town once 
per week. Mentorship for trainees is often provided by placement students in the field of social work, recreational therapy or inclusive outdoor recreation from both Lakehead University and Confederation College. This environment enables many of the trainees to have the opportunity to learn kitchen skills that can be applied in day to day living and in future employment. Feedback on the success of the Soup and Bread Extravaganza and the increasing demands from individuals wishing to take food service training, led to the expansion of the model to a Pizza and Salad program, and the introduction of local seasonal berry pies and Harvest/Holiday Baskets.

The four cofounders of WSCC were all gardeners and artists by trade. Most of their work was inspired or created from natural materials growing on and around the property. Through partnerships with professional gardeners and people trained in Horticultural Therapy, WSCC began taking a leadership role in providing opportunities for those working in the helping professions to gain skills in bringing the physical and mental health benefits of working with plants, gardens, and the unique northern landscape to their clients through a Therapeutic Gardening Certificate program.

The market, soup and bread and horticultural therapy program have multiple purposes including individual development, skill building and social benefits. Access to the market for the Lappe community allows income generation for Willow Springs, vendors and trainees. Willow Springs assists trainees and small, local vendors and as a result, creates increased community resilience. Social innovation, entrepreneurship and economic diversification are the direct result of job skills training, adjusting to the changing needs of the populations served and creating new partnerships to provide vendors with new economic opportunities.

Examining the activities of WSCC through the CAS approach reveals a social economy initiative that is rooted in place and responsive to a dynamic context, while reinvesting economic gains in its social benefit activities. The activities of WSCC are grounded in the immediate landscape of the centre and proudly and uniquely northern. They leverage a large network of over 18 local community service providers to support their work and they respond promptly to feedback loops. This interdependence within a tight network of community organizations spanning the social services, food, art, and environmental sectors, enables the organization to adapt quickly and find and fill niches of community need. Examples of social services include programs for people with special needs, mental health programs, senior centres and corrections. All of the programs at WSCC have emerged from these diverse connections, with each initiative creating the momentum for subsequent initiatives.

\section{Bearskin Lake First Nation}


Bearskin Lake First Nation (BLFN) community is situated in scattered pockets of homes spread around Michikin Lake, which flows north into the Severn River, one of the largest river systems in Ontario, and empties into Hudson Bay. The land and northern flowing water system are bountiful with traditional food sources. People have lived in this area since the glaciers receded thus forming generational connections with the land and waterways as food sources. The on-reserve population is 446 with an additional 426 living off reserve. The community is part of Treaty 9 territory and part of the larger Nishnawbe Aski Nation governed area. The people of BLFN are removed from mainstream society to some degree by distance. Travelling to and from the community of BLFN takes planning and is quite expensive. Most goods (clothing, food, household items, fuel, etc.) are shipped via air and the freight alone is costly. During the coldest months of the year an ice road can be used to travel through the small town of Pickle Lake to other urban towns and cities. This short ice road season also enables people to travel by skidoo and truck to visit family and friends, and to attend outside community events such as fishing derbies, bingos, hockey tournaments, and jamborees, and to offer support in times of loss or crisis. The ice road provides the opportunity to bring in goods and reduces the cost of shipping during the two to four months that it is accessible depending upon climatic fluctuations. Travel by ice road to transport bulk food, fuel and other heavy necessities is always hazardous, made more so now by seasonal weather fluctuations.

BLFN has an airport, diesel generating station, water treatment facilities, garage, landfill site, post office, elementary school, offices for distance education and Internet high school, health centre/nursing station, two stores that sell food- externally owned Northern Store and community-owned Co-op, a police station and various offices to carry out administrative and government supported social services within the community. There are three churches, a radio station and recreation facilities also in the community. In the warmer seasons, the community has a beach and feast grounds with a stage, boat launch and tipis to celebrate events.

Food security can be challenging in northern, land-based community food systems. However, the varied relationships between First Nation communities and subsequent waves of European and then Canadian governments, and their policies and practices, as well as the ongoing expansion of the capitalist economy have produced additional challenges to food security in communities such as BLFN. This expansion of the western and capitalist approach created an imbalance for one side of the treaty signatories (Assembly of First Nations, 2011; Harring, 1998; Manuel \& Derrickson, 2015).

The Elders have spoken of the broken treaty agreements that were made in the early twentieth century. One of the agreements included the development of shared knowledge and tools for harvesting new foods within the First Nation communities. This treaty agreement was never written into the official treaty document. This is one example of the historical barriers Indigenous people have faced in Northern Ontario. In spite of these 
challenges, the traditional lifestyle of hunting and gathering wild foods has been preserved and is still practiced.

BLFN community members maintain a strong connection to the values, language and customs that were present prior to the time of contact with Europeans. Most members speak Anishiniimowin, or Oji-Cree, and there are efforts to continue teaching the language to the younger generations. Traditional values are revealed through the respect for all living things from young children to elders and animals on the land; by preserving the lands and waters; and using the resources from their traditional territories. Social economy began as a way of life, not as an off-shoot of the mainstream industrial economy (Nelson \& Stroink, in progress). Concepts of social economy and food sovereignty merge within this context. Identity is deeply embedded in the land which is the traditional giver of food. Food is viewed as a medicine to create well-being.

BLFN places high priority on holistic social and ecosystem health benefits over profit and thus demonstrates key features of a social economy. There is a sharp distinction made between community well-being and market enhancement. The community views the outside economy and external government and its policies as "just a phase". For members of BLFN, primacy is given to the "law of the land" whereby in-depth feedback is constantly active to assess what is happening within ecosystem-human relations. While the community is very much aware of how external legislation starting with the Indian Act holds influence, from a generational perspective it still is viewed as "just a phase". Land and identity with the land supersedes all outside influences. Trust and respect are vital for community relationships and interactions to thrive.

Utchete (in Oji-Cree) is a concept referring to the idea that if you put goodness in, goodness will come back to you. As such, Utchete creates a state of community spiritual balance. Likewise, exhibiting negativity may create feedback that disturbs healthy positive well-being that can impact on the community and individual and family members. The BLFN community practices a culture that holds strong to distinctive Indigenous ways of knowing, balance and relationship with land and water. For example, there is resistance around some of the guidelines put out by the Ministry of Natural Resources (MNR), but community members rarely speak of it directly. Moreover, this hesitation in disrupting spiritual balance raises concern with selling fish to market because of the different stewardship approach and the potential implications of commodification and ecological protections. Nevertheless, discussions with traditional knowledge keepers are underway to consider applying for a commercial fishing license to expand local food security.

Through Utchete, stewardship values, not a quest for profit, drives food activities and trade. The community does not want to be dependent on charity with outside communities for food but seeks instead to work as a partner with neighboring communities to develop adaptive resiliency. Ideally, trade would be among First Nation communities that can be reasonably accessed through ice roads, boat, all-terrain vehicles and skidoos. Trade among neighboring communities can be done with stewardship values if it is done 
independently of both the market economy and government money. The desire is to distribute local foods and crafts within community first before selling externally, so that the cultural significance of the craft stays within community and food is kept local when possible.

Members of BLFN have adapted contemporary tools to augment the traditional social economy of sharing food. Michikan Auction Wars is a page on Facebook for Bearskin Lake members and communities that are close enough to be reached by all-terrain vehicles and snow machines. BLFN members trade and sell baked goods and meals quickly and easily through this page on Facebook. This type of informal food economy is not a new one in Bearskin Lake, but it is one that could be further expanded on a larger scale. On the Michikan Auction Wars, there are crafts, clothing, children's toys and household items listed as well as food.

The Bearskin Lake community organizes many community events that focus on healthy living. Hunting and harvesting festivals enhance social capital and resilience by rebuilding knowledge and skills of traditional diets. These festivals and other customs are ways of giving thanks and sharing the food that has been provided. Community fundraisers such as flea markets, penny sales and bingos ensure that these festivals, celebrations, and customs are possible. During Christmas festivities, the community hosts a month-long array of activities including a frozen turkey hunt. The recreation workers place $10-20$ turkeys all over the community during the night then host a turkey hunt the morning after. This is one example where Bearskin Lake's social economy is able to aid community members in need, while having fun together with family and friends. The band council encourages these types of activities in order to foster a positive approach to assisting those who struggle with basic needs.

These initiatives of Bearskin Lake First Nation reveal a social economy of food that has historical roots long pre-dating the capitalist economy, as well as contemporary adaptations of technology. This combination of adaptations with land and culture rooted in place plus economic activities and tools all mobilized with the aim of achieving social and ecological benefits are consistent with the defining features of social economy in a uniquely Northern manner. The processes through which these social economy features emerge in BLFN are also usefully understood with the complexity science approach. Members of the community engage with each other, with the land, and with other communities as independent yet interdependent agents in pursuit of collective survival and well-being.

Through Utchete, the independence of community members is respected, while the focus is on the interdependent functioning of the community as a whole. People's interactions with each other and with the land are dynamic and responsive to change. For example, access to traditional foods and ice-road access to outside food sources vary by seasons, and the reliability and safety of ice-roads increasingly vary within seasons as a result of climate change. The people continue to adapt to these pressures, as in the use of 
social media to facilitate food exchange.

\section{Cloverbelt Local Food Co-op}

Before Cloverbelt Local Food Co-op (CLFC) was founded in 2014, there was a concern that the agricultural community in Northwestern Ontario was becoming smaller, disjointed, and unable to attract new producers. Overall options were limited to seasonal markets that required producers to spend ten or more hours each week traveling to these widely scattered markets rather than spending this time on farm production and processing. They could sell at the Farmers' Market, which operated in Dryden and the nearby township of Oxdrift, Sioux Lookout, Vermillion Bay and Kenora, but these markets only ran during the summer and early fall months when fresh produce was abundant. It was also difficult for some farms to have the capacity to regularly supply seasonally.

From this position where growth in local food production seemed stagnated, there emerged a desire among farmers in the Dryden area to be better connected for producer and processor support, knowledge transfer among producers and processors, and local food distribution. Explained as an adaptive cycle, the producer and processor were locked into a local food system where they were responsible for both producing or processing and marketing. They reorganized to accommodate the release of the knowledge of the land and its production capabilities, the skills of the producers and processors and the desire of regional consumers for access to naturally grown foods.

The emergence of CLFC as the first online co-op system in Northwestern Ontario overcame many of the obstacles faced uniquely by farmers and consumers wanting a food system in the north that was sensitive to the conditions where a sparse population is spread over a vast geographic area. The location in Dryden held many local advantages for the emergence of an on-line co-op as Dryden is the geopolitical centre of the region, with air, road, and railway connections from Thunder Bay to Winnipeg which makes it well situated as a central road and air distribution point for communities across the region, allowing CLFC to scale up and establish hubs in multiple locations.

The CLFC grew quickly and its vision "to become the central hub for production and distribution of local goods in Northwestern Ontario" resulted in a dramatic re-spatializing of how local foods could be distributed. Within one year, the Dryden hub was joined by a hub in Sioux Lookout and then the neighbouring city of Ignace. Four years later in 2018 there are eight regional hubs with several more potentials in the near future. A complexity approach helps to explain how local food was distributed - from only seasonal markets where each producer and processor were responsible for their own marketing to a collective approach facilitated by an online ordering system. This structure quickly led to an uptake of locations to access local food and to the number of producers, processors and consumers. While the vision was clear from the beginning, the hubs and participants were an emergent and non-linear process that is best 
described as a self-organizing distributed control pattern. A community shows interest by supporting the location of a community-based hub. Diversity seems to be the pattern as each of the eight hubs has a different type of distribution centre such as a restaurant, volunteer bureau, a chamber of commerce tourist information centre, and an agriculture centre. Next the potential community hub gathers consumer members on-line.

A desire to have greater connections rather than competition among farmers in the Northern Ontario region and building connections within and between communities is a major part of everything CLFC does. This is a striking change from the previous distribution practices where each producer and processor typically attended 5- 7 different seasonal markets each week where they competed against each other. The online marketplace means that producers and consumers re-socialize so that they are supporting each other and connecting from different communities in NWO that may not have been previously able to buy and sell from each other.

As a complex adaptive system, CLFC producers and processors are able to learn from experience, alter their behaviour in response to changes in the context such as weather patterns, fluctuations in consumer demands, and competition from the external industrial food system. The producers and processors gain quick feedback through the on-line system where the consumer has easy access to email the local food system supplier about production practices or queries about products being sold.

The online system supports autonomous management, a key characteristic of a social economy. Each supplier independently determines each week what products they have available and to which local food community food hubs they wish to distribute their produce. In this way, the online system is very democratic, another key characteristic of a social economy. The benefit to producers is that they have flexibility in what they offer. If they run out of a certain product in a given week, they simply do not have to list it. Producers can offer what is in season and adapt to weekly demands. Because producers decide how much of their product they want to make available each week, there is no pressure for them to meet specific quotas or quantities. This means they can adapt to things like changing seasons or test out new products to see how well they will sell. The online system enables a prompt feedback loop mechanism to get direct feedback from their consumers. This flexibility is one of the main reasons that CLFC has grown so significantly in such a short time. Finally, without a physical storefront, there are no additional expenses for storage or inventory. Moreover, the on-line way of operating is appealing to young producers.

CLFC's on-line system reinforces autonomous management from choice of products, to writing their own on-line information about their farm or process facility and setting weekly the prices on their products. There is no central administrative control over what one should say about their farm or processing facility nor are there any regulations on pricing of products. Instead, a complexity approach demonstrates how the processors and producers are independent and unpredictable in what they may offer each week. However, they are actively interdependent in reaching out to community consumers across Northwestern Ontario. Thus, when one supplier 
changes the pricing it changes the pricing context for others. Thus, the suppliers adapt to changes either up or down in pricing.

Sharing is exemplified by encouraging support networks among producers and between producers and suppliers. In order to support this collaboration of producers and processors, CLFC began a Regional Food Mapping and Distribution Project which pinpoints the locations of local food contributors in NWO on an interactive online map ${ }^{2}$, including producers, distribution centres, processing facilities, and restaurants serving local food, along with a description and the contact information of each. Having all this information in one place allows consumers to know exactly where their food comes from and means that producers can see restaurants nearby to whom they might sell their products, as well as other producers with whom they might share transport, storage, or equipment. The map can also be used to plan transportation routes. New producers or those looking to expand their production can use the map to identify what types of products are not currently available and where there may be potential markets. As CLFC operates primarily online, it can be difficult for members to connect. The map helps to overcome this challenge. There is also significant potential for the map to be used in the future to establish hubs in new communities, including remote, fly-in First-Nations communities. CLFC's Regional Food Map is prefaced by a statement that prioritizes social benefit over profit. Each time a consumer, producer, processor or restaurant uses the map, they are reminded of the priority placed on CLFC as a vibrant component of community and the regional area.

Interdependence is exemplified through the community partners and other sponsors that have played an immense role in CLFC's expansion and success. These networks of individuals and organizations have supported CLFC, helped get the online co-op off the ground, and continue to work alongside it. These partnerships across the NWO region are essential for the coop's continued success. Connections with organizations that prioritize social values drive a stronger local food movement.

As of 2018, what started with just 85 members in the Dryden community has now grown to a membership of 1,749 in nine communities across NWO, with expansion to more communities currently under way. As hubs grow larger and demand increases, CLFC adapts to each location's needs. Some hubs currently only operate once a month, but this structure is not rigid and allows for expansion along with sales. This adaptability is imperative for sustainability.

CLFC helps to strengthen the economy and social relationships within communities, increasing each community's ability to adapt to challenges, but it also strengthens ties between communities, increasing the adaptive resilience of NWO. Prioritizing social benefits over profits is a pivotal characteristic of a social economy. Previously, much of the produce in these communities was brought in from other places such as Southern Ontario and Manitoba, and the economic and social benefits of food production would leave the area. But people are starting to realize that they know their local strengths and demands better than anyone else, and producers

\footnotetext{
${ }^{2}$ http://www.nwofoodmap.com
} 
can capitalize on this for their own economic benefit and more importantly the community's overall benefit. With more local producers, there is the opportunity for more facilities for processing, storage, grading eggs, etc., which in turn means more jobs, more capacity for local food, and the cycle continues. Local investments pay off.

The community greenhouse is invaluable to CLFC for a number of reasons. First, it allows the co-op to add to the amount and diversity of food that it produces, so that there are more options offered to consumers. It also lengthens the growing season, as the warm environment means that seeds can be planted earlier, and plants can continue to grow later into the fall. This is advantageous in a cool, northern climate and helps to ensure that local demand can be met. Second, the greenhouse acts as a visible structure for CLFC and for local food. Third, education is an integral part of CLFC; and the greenhouse offers a physical location for events and workshops to take place. A number of classes from local elementary schools are given tours and offered plots in the greenhouse each year, where they can learn about how their food is grown and get hands-on experience in growing themselves. Students learn about how far food in the grocery store travels to get to them and how it loses its nutritional value in the process; the advantages of growing and eating local food; and how easy it can be to do this. The food grown by the students has also been used in meal programs at the schools, so they directly benefit from the hard work they put in. Getting children interested in local food at a young age is the first step for some of these children to become the next generation of producers for the co-op. In this way the greenhouse supports not only the short-term growth of CLFC, but its long-term growth as well.

CLFC provides a self-organizing opportunity for people to start new businesses or expand their existing customer base; and there are a lot of producers whose main source of income is what they sell through CLFC. Other producers use it as a secondary source of income, or only sell at certain times of the year or when it is convenient to them. Overall, there is plenty of room for diverse economic activity; producers do what works best for them. Producers are able to share facilities, reduce costs and work together rather than compete. Although CLFC is still relatively young, it has already enhanced access to local food, supports events that encouraging consumer growth in understanding the health benefits of local food; and keeps money recycling in Northwestern Ontario. With an adaptive mindset, the co-op's growth can remain tenable, and it can continue to connect people, support them in doing what they love, educate them, and overall strengthen the NWO region.

\section{Discussion}

In this paper, we have explored four social economy of food case studies from Northwestern Ontario, demonstrating the key characteristics of the initiatives. The pursuit of social and 
ecological benefits, such as enhancing access to local food or supporting community inclusion and well-being, is the prevailing purpose of each initiative, with profits re-invested in these activities. The four initiatives vary in their organizational structures, but in each one there is autonomy from government, and decision making is generally democratic. Two exceptions to this latter social economy characteristic are Algoma Highlands and Arthur Shupe Wild Foods, which are both social enterprise initiatives run by their owners. Thus, we argue that these initiatives are consistent with the defining characteristics of social economy. It is notable that not one of the people we interviewed in the case studies referred to their initiative as a social economy. This lack of self-identification with the concept of social economy has similarly been noted by Southcott (2009) in his study of Northern economies. This is an interesting finding for future research on the nature of social economies.

In addition to drawing these connections between the four case studies and the characteristics of social economy, we have demonstrated how the complexity science approach can illuminate the social economy initiatives in novel ways. As complex adaptive systems, each case study involves the interactions of a set of independent yet interdependent agents. For example, in CLFC, the producers, processors, consumers, and organizers are independent of each other but also interdependent in that their actions (e.g., how much of a given product to make available as a producer) collectively create the context to which the other agents respond with, for example, their amount of purchasing. This in turn creates the context to which the producers again adapt. Through these interdependencies, system-level properties emerge as patterns which adapt through feedback loops to the context. In these case studies, we have demonstrated that the social economy initiatives adapt continuously to aspects of their specific context. These aspects of context include the biophysical (e.g., conditions of the land favouring blueberries, changes to ice-road availability), technological (e.g., online platform enabling CLFC to form, use of social media for food trade in BLFN), social (e.g., the need for inclusive training opportunities for Willow Springs), and economic (e.g., rising demand for local food in the market for CLFC and the blueberry initiatives).

The adaptive cycle describes how system behaviour that is adaptive in context stabilizes with supporting structures until those structures reduce resilience, undermining the system's ability to adapt to changes in context (Gunderson \& Holling, 2002). At this point the structure is released and a new round of experimentation and reorganization occur once again in adaptation to the context. Each of the studied initiatives has a structure that has formed through adaptation and supports stability and efficiency; some are more densely or formally structured (e.g., CLFC) than others (e.g., AYBI, BLFN), but none are deeply into the conservation phase. Indeed, there is evidence that each initiative is engaging actively in assessing and responding adaptively to their contexts, indicating that resilience is still high.

This complexity science approach allows us to view social economy initiatives as systems instead of as entities, as dynamic and adapting in context instead of as a list of features in categories. With the complexity science approach, we are able to describe how the nuances of context set the initial conditions from which uniquely patterned system properties emerge in 
place. The complexity approach reveals how these social economy initiatives have emerged to re-spatialize and re-socialize the food system in Northwestern Ontario.

\section{Conclusion}

We discovered that all of our social economy initiatives have demonstrated their influence on respatializing and re-socializing conventional food system approaches as they provide social, economic and environmental benefits to their local and regional communities. We observed that our social economies of food systems did not simply enhance access to local foods but changed many social interchanges and relationships within each initiative. Likewise, these case studies provided unique ways to utilize the boreal forest land best to enhance access to local food. We conclude with a few examples of how each social economy has adapted within context to impact the conventional food system. The AYBI social economy at Aroland First Nation has resocialized the food system through a social economy that brings all ages together in activities around blueberry foraging which is in stark contrast to other programs where food is accessed through strict criteria of eligibility. WSCC has re-spatialized by having a significant impact on helping local small-scale farms and processors learn how to market their produce so as to enhance access to local food. They also have drawn a strong connection between boreal forest plants and therapeutic well-being through their horticultural therapy program, providing another adaptive social benefit based on the unique context of Northwestern Ontario.

The Nipigon Blueberry Blast has re-socialized the community by adding opportunities to enhance relationships within the community and to reach out and attract tourism opportunities. In BLFN the desire to focus on an intra-trade food system among communities that can be reached by all-terrain vehicles and ice roads, in contrast to exporting to non-First Nation communities is heightening opportunities for building stronger relationships and to collectively engage in food celebrations such as the Hunter Festival. Through CLFC's success in becoming the regional hub for production and distribution of local goods in Northwestern Ontario has resulted in a dramatic re-spatializing of how local foods are accessed. Arthur Schupe's Wild Foods for decades has demonstrated the viability of a social enterprise focused on local boreal food sources of blueberries and mushrooms. Algoma Highlands has further demonstrated the viability of the local food system by initiating the first private enterprise for blueberries in Northern Ontario.

Feedback from the success of this initiative has re-socialized an area hit hard by forest and mine closures by providing new employment opportunities to expand to other native food sources such as raspberries and to expand innovative processes such as blueberry jams, wines and Mooseradish. Feedback from these successes has led to opening a store front on the TransCanada Highway that is attracting new community entrepreneurs that provides further adaptations that broaden the scope for new employment and artistic endeavours.

Through the use of a complexity science approach, we have illuminated the internal dynamics of social economy initiatives emerging and adapting within their contexts. The 
initiatives described in our four case studies embody characteristics typical of social economies; yet also take on unique character elements as a result of their emergence in place. Collectively, these social economy initiatives have the effect of building a food system that re-introduces the social and spatial dimensions of the food system.

Acknowledgements: We are grateful for the support through the Northern Node of the Nourishing Communities Initiative funded by SSHRC Insight Grant Social Economy of Food: Informal, Under-recognized Contributions to Community Prosperity and Resilience Project. We are grateful to all the communities and individuals who shared their experiences with social economies in a northern context.

References

Amin, A., Cameron, A., \& Hudson, R. (2002). Placing the social economy. London: Routledge.

Assembly of First Nations (2011). Sacred Treaties - Sacred Trust: Working Together for Treaty Implementation and Advancing our Sovereignty as Nations. AFN National Strategy on Treaty Implementation. Retrieved from https://www.afn.ca/uploads/files/archive/18.pdf.

Canadian Community Economic Development Network (CCEDNet Ontario). (2008). A community's agenda for strengthening Ontario's communities. Retrieved from https://www.ccednet-rcdec.ca/en/page/tools-publications.

Chantier de l'economie sociale. (2013). Social economy reference guide. Retrieved from http://chantier.qc.ca/wp-content/uploads/2017/08/guide-de-reference-sur-l-economiesociale-anglais.pdf.

Charron, A. (2012). The growth of the social economy in Quebec through the unification of the movement since 1996. The Canadian CED Network. Retrieved from https://ccednetrcdec.ca/sites/ccednet-rcdec.ca/files/ccednet/Alex_Quebec_paper.pdf.

Cummings \& Associates. (October, 2009). Thunder Bay district agriculture impact study. Guelph, ON: Harry Cummings and Associates. Unpublished report. Retrieved from http://www.nodn.com/upload/documents/thunder-bay-district-agri-impact-reportfinal- oct.-26-2009.pdf

Dawson, K.C.A. (1983). Prehistory of the interior forest of Northern Ontario. In A.T. Steegmann Jr. (Ed.), Boreal Forest Adaptations: The Northern Algonkians (pp. 55-84). New York: Plenum Press.

Defourny, J., \& Develterre, P. (1999). The social economy: The worldwide making of a third sector. In J. Defourny, P. Develtere, \& B. Fonteneau (eds.), L'économie sociale au Nord et au Sud (pp 3-31). Hiva (Universiteit Leuven) et CES (Université de Liège). 
Downing, R., McElroy, R., Tremblay, C., \& Amyot, S. (2012). Converging agendas for the social economy and sustainable development. In R. Downing (ed), Canadian Public Policy and the Social Economy (pp. 329-374). Victoria, BC: University of Victoria.

Golob, U., Podnar, K., \& Lah, M. (2009). Social economy and social responsibility: alternatives to global anarchy of neoliberalism?", International Journal of Social Economics, 38(5): 626-640.

Gunderson, L.H., \& Holling, C.S. (2002). Resilience and adaptive cycles. In L.H. Gunderson, \& C.S. Holling (Eds.), Panarchy: Understanding Transformations in Human and Natural Systems (pp. 25-62). Washington, DC: Island Press.

Harring, S.L. (1998). White man's law: Native people in nineteenth-century Canadian jurisprudence. Osgoode Society for Canadian Legal History, Toronto: University of Toronto Press.

Heynan, N., McCarthy, J., Prudham, S., \& Robbins, P. (Eds.) (2007). Neoliberal environments: False Promises and Unnatural Consequences. New York: Routledge.

Holland, J. H. (2006). Studying complex adaptive systems. Journal of Systems Science and Complexity, 19, 1-8.

Holling, C.S. (1973). Resilience and stability of ecological systems. Annual Review of Ecology and Systematic, 4, 1-23.

Holling, C.S. (2001). Understanding the complexity of economic, ecological, and social systems. Ecosystems, 4(5). 390-405.

Hudson, R. (2009) 'Life on the edge: navigating the competitive tensions between the 'social' and the 'economic' in the social economy and in its relations to the mainstream.', Journal of Economic Geography, 9(4), 493-510.

Hun, L.S., \& Endo, C. (2016). The development of the social economy in the welfare mix: Political dynamics between the state and the third sector. The Social Science Journal, 53(4), 486-494.

Jennings, D. (2012). Summary Report and Literature Review. Auckland: New Zealand Community Economic Development Trust.

Kay, A. (2006). Social capital, the social economy and community development. Community Development Journal, 41(2), 160-173.

Malloy, A., McFeely, C., \& Connelly, E. (1999). Building a social economy for the new millennium. Derry: Guildhall Press/NICDA.

Manuel, A., \& Derrickson, R.M. (2015). Unsettling Canada: A national wake-up call. Toronto: Between the Lines.

Matei, A., \& Antonie, C. (2015). Complexity theory and the development of the social innovation. Procedia - Social and Behavioural Sciences, 185, 61-66.

Mendell, M., \& Neamtan, N. (2009). The social economy in Quebec: Towards a new political economy. In L. Mook, J. Quarter, \& S. Ryan (Eds.), Why the social economy matters (pp. 32-58). Toronto: University of Toronto Press. 
Mitchell, M. (2009). Complexity a guided tour. Toronto: Oxford University Press.

Morcol, G. (2014). Self-organization in collective action: Elinor Ostrom's contributions and complexity theory. Complexity, Governance \& Networks, 1(2), 9-22.

Moulaert, F., \& Ailenei, O. (2005). Social economy, third sector and solidarity relations: A conceptual synthesis from history to present. Urban Studies, 42(11), 2037-205.

Myers, J. (2009). In search of...Exploration of the boundaries, scope and definitions of the social economy: a discussion paper. Social Economy and Sustainability Research Network. Mount St. Vincent University: Halifax, NS.

Nelson, C. H., \& Stroink, M. L. (2014). Accessibility and viability: A complex adaptive systems approach to a wicked problem for the local food movement. Journal of Agriculture, Food Systems, and Community Development. (Advance online publication.)

Nelson, C. H., Stroink, M.L., \& Kerk, K. (2015). Northern Ontario: A resilient connected food hub: Case study. Lakehead University: Food Security Research Network. Retrieved from http://casestudies.fsrn.ca/.

Nelson, C.H., \& Stroink, M.L. (2019). Exploring the unique aspects of the northern social economy of food through a complexity lens. Submitted October, 2018 for publication in January issue of Northern Review.

Nokiiwin Tribal Council (nd). Retrieved from http://www.nokiiwin.com/robinson-superiortreaty.

Ostrom, E. (1990). Governing the commons: The evolution of institutions for collective action. Cambridge: Cambridge University Press.

Ostrom, E. (2010). Beyond markets and states: Polycentric governance of complex economic systems. American Economic Review, 100, 1-33.

Qian, B., Hayhoe, H., \& Gameda, S. (2005). Developing Daily Climate Scenarios for Agricultural Impact Studies. Presented at the 16th Conference on Climate Variability and Change, January 9, San Diego, CA.

Randle, J., Stroink, M.L., \& Nelson, C.H. (2014). Addiction and the Adaptive Cycle: A New Focus. Addictions, Research and Theory, 23(1), 1476-7392.

Restakis, J., (2006, January). Defining the social economy - The B.C. context. Prepared for the BC Social Economy Roundtable. Retrieved from http://www.msvu.ca/socialeconomyatlantic/pdfs/DefiningSocialEconomy_FnlJan1906.pd f.

Sims, R.A., \& Baldwin, K.A. (1991). Landform features in Northwestern Ontario. COFRDA Report 3312. NWOFTDU Technical Report 60. Sault Ste. Marie, ON: Forestry Canada, Ontario Region.

Sonnino, R., \& Griggs-Trevarthen, C. (2013). A resilient social economy? Insights from the community food sector in the UK. Entrepreneurship and Regional Development, 25(304), 272-292. 
Southcott, (2009). Introduction: The social economy and economic development in northern Canada. The Northern Review, 30, 3-11.

Stacey, R. D. (1996). Complexity and creativity in organizations. San Francisco: Berrett-Koehler Publishers.

Stolz, W. (2018). Coming to know through story: exploring the social economy of blueberry foraging in Northwestern Ontario. Lakehead University, unpublished thesis.

Stroink, M.L., \& Nelson, C.H. (2013). Complexity and food hubs: Five case studies from Northern Ontario. Local Environment: International Journal of Justice and Sustainability, 18(5), 620-635.

Stroink, M., \& Nelson, C.H. (2009). Aboriginal health learning in the forest and cultivated gardens: Building a nutritious and sustainable food system. Journal of Agromedicine, 14, 263-269.

Walker, B., \& Salt, D. (2006). Resilience thinking: Sustaining ecosystems and people in a changing world. Washington: Island Press. 